University of South Carolina

Scholar Commons

7-1993

\title{
Linking Teacher Educators, Knowledge, and the Quality of Practice in Schools
}

Murrary F. Mitchell

University of South Carolina - Columbia, mmitchel@mailbox.sc.edu

Follow this and additional works at: https://scholarcommons.sc.edu/pedu_facpub

Part of the Education Commons

\section{Publication Info}

Published in Journal of Teaching in Physical Education, Volume 12, Issue 4, 1993, pages 399-412. http://journals.humankinetics.com/jtpe-contents (C) 1993 by Human Kinetics Publishers, Inc.

This Article is brought to you by the Physical Education, Department of at Scholar Commons. It has been accepted for inclusion in Faculty Publications by an authorized administrator of Scholar Commons. For more information, please contact digres@mailbox.sc.edu. 


\title{
Linking Teacher Educators, Knowledge, and the Quality of Practice in Schools
}

\author{
Murray F. Mitchell \\ Rutgers University
}

Children in this country are entrusted to teachers in schools for 5 hours a day, 5 days a week, approximately 36 weeks a year, for 12 to 13 years. Citizens concerned with the future want to know if the children of today are being prepared for the world of tomorrow. Parents want to know what is being done to and for their sons and daughters. And in these times of financial cutbacks, taxpayers want to know where their tax dollars are going. There is widespread belief that schools in general, and teaching in particular, should be much better today than 5,10 , or more years ago. There is, furthermore, both a belief that teaching and schools are not appreciably better than they were and a certainty that the educational system is not as good as it should be. The responsibility for controlling the quality of what teachers do in schools is handled by a variety of different people and institutional mechanisms. The purpose of this paper is to examine one group of individuals - teacher educators - and the ways they exert influence on the quality of practice in schools.

Ideally, those who work in colleges and universities, including teacher educators, contribute to what goes on in schools in at least four related ways. One contribution comes in the form of a gatekeeping function: allowing only those who have successfully demonstrated the "appropriate" skills to enter into the profession. A second contribution is made by preparing teachers to enter schools. Teachers need the skills to cope with the challenges of today and the ability to adapt to the changing demands of tomorrow; skills and abilities should be acquired from university programs where the latest and most effective strategies have been researched and refined for application. Third, disseminating the results of one's own research and interpreting the implications of others' work is a responsibility of teacher educators. Fourth, scholarly productivity is a prime responsibility of professors. Through these last two contributions of creating and interpreting research, current and future teachers may learn the best and most appropriate goals and strategies for teaching. Ideally, all of these responsibilities are woven together to yield informed professionals who can create and run quality physical education programs in the school system.

But the process seems to break down. Evidence of the breakdown of the relationship between actions of teacher educators and practice in schools can be identified on several levels. For example, very few professors (including physical education professors) appear to be involved in research and publication (Burch, 1989; Carnegie Foundation for the Advancement of Teaching, 1985; Ducharme \& Agne, 1982; Freeman, 1977; Ladd \& Lipset, 1976; Metzler \& Freedman, 1985; Mitchell, 1992a, 1992c; Mitchell \& Lawson, 1986; Scott, 1986). Moreover, few professors appear to even read much of what is published (Metzler \& Freedman, 1985; Mitchell, 1992c; Sykes, 1988). Hence, there is a dismally small chance that much of what is current or "cutting edge" knowledge is passed on to practicing teachers through inservice programs prepared and delivered by teacher educators, to aspiring teachers as they are prepared to enter the field, or to teacher educators as they construct their own programs 
of teacher preparation and screen aspiring professionals at entry into and/or exit from their programs.

There is a growing body of literature related to teaching physical education available to inform the process of teaching and teacher education (Bain, 1990; Locke, 1984; Mitchell, 1991). Teachers have access to this work even if their professors did not use it and did not pass on insights from the literature. However, there is support for the observation that teachers tend not to look to the research for insights into their own practice (Earls, 1981; Lawson, 1992c). Lawson proposed four possible explanations for this teacher behavior: (a) The research and related findings may be unattractive to practitioners because of flaws, gaps, and apparent contradictions that render the work inapplicable to the world of practice and unusable by practitioners; (b) the research is not adequately disseminated to practitioners either through professional preparation programs, professional associations, or practitioners' work environments (i.e., schools); (c) accreditation and certification systems may be partially responsible because these systems are neither based on a research foundation to support the value of their standards, nor do they look for evidence of research utilization skills in students being certified; and (d) practitioners, themselves, may be responsible for not looking to the research for insights into practice because they may not perceive a need to look to the research for solutions to work problems. In fact, they may even avoid this source of potential insight into their work for a variety of reasons.

Another plausible explanation may be tied to behaviors modeled by teacher educators. Many physical education teacher education (PETE) faculty tend not to read the researchoriented journals both within the physical education field or within the more generic education field (Metzler \& Freedman, 1985; Mitchell, 1992c). As a result, PETE faculty may exert a strong influence toward research avoidance tendencies in contrast to their espoused value of research (cf., Mitchell, 1988). Zeichner and Tabachnick (1981) suggested a similar notion for teacher preparation programs in other areas; programs may exert a powerful influence over professional behaviors that are contrary to those formally advocated by the faculty of the program.

This paper will begin with an examination of teacher educators in general, and PETE faculty in particular. Potential contributions of teacher educators to the quality of practice in schools will be explored. The concept of "knowledge" will be included to illustrate how the ways that "knowledge" is identified affect how it is created, disseminated, and utilized. Throughout the chapter, the links among teacher educators, knowledge, and the quality of practice in schools will be explored for the potential to create programs that deserve a place in the lives of children.

\section{Teacher Educators}

Identifying roles played by teacher educators is problematic. Few people agree on the criteria for identifying teacher educators. Although attempts have been made to create conceptual models identifying different types of teacher educators in general (cf. Carter, Griffin, \& Brown, 1981; Massanari, Drummond, Houston, \& Edelfelt, 1978; Ryan, 1974) and PETE faculty in particular (cf. Mitchell, 1990b), none of these models has yet captured the uniqueness of physical education, and no single model has been accepted as adequately representative of all who have an interest in and make contributions to teacher education. Teacher educators are a diverse group of individuals who are difficult to categorize due to differing values and views of their own professional behavior - a situation no doubt tied to the variety of career paths taken by these individuals to become professors. The most consistently identified, shared trait of these faculty members appears to be the inverse relationship noted between prestige and degree of involvement with the formal education of teachers (Borrowman, 1965; Judge, 
1982; Lanier \& Little, 1986). With particular reference to a sample of physical education teacher educators, Metzler and Freedman (1985) concluded that "there is no professional pursuit, responsibility, academic content, or mission that binds the group; it is a group by default, not by design', (p. 133).

Due to the complexity of different types of teacher educators and the differing tasks performed, only selected role responsibilities of teacher educators in higher education will be highlighted. In particular, responsibilities to be discussed include the following: the role of gatekeeper over entry into the field; the responsibility to prepare new teachers; the dissemination (or interpretation) of knowledge role; and the role of knowledge producer.

\section{Gatekeeping Role}

The gatekeeping responsibility of teacher educators is found in at least three points during academic programs. Gatekeepers must decide who should be eligible to enter professional preparation programs; who is making sufficient progress toward a degree throughout the program to continue; and who has demonstrated adequate competence in designated knowledge, skills, attitudes, and values to be allowed to graduate and gain certification. Accurate evaluations regarding these decisions can save time and money for students. Spending 4 years in time and money to discover that one is not likely to become a successful teacher is an expensive lesson. When students unlikely to succeed can be counseled out of the program early, they then may be able to identify an alternative career track. Furthermore, the department has a vested interest in preventing students who are not likely to succeed from participating in practical experiences with children in the schools. First, there is a responsibility to safeguard children from incompetent instructors. Second, there is a reputation to protect with teachers who judge programs by their graduates-repercussions can be felt through the acceptance or refusal of student teachers and the employment rates of program graduates.

The three decision points of the gatekeeping role pivot around the question "Who should and who should not teach?" What is the basis for answering this question? Martens (1987) reviewed the related literature in education and physical education and concluded that "there is more rhetoric on the need for selection and for more sophisticated methods than there is productive research"' (p. 413). Martens noted that the most common basis for making these decisions was grade point average (GPA). Unfortunately, correlations between GPA and subsequent teaching evaluations have been variable but low. Correlations between other selection criteria (i.e., fitness tests, hand-eye coordination, interviews, motor skill performance tests, personality ratings) and subsequent teaching evaluations were also low. Diminishing resources, high interest in the major, and a commitment to doing the best job possible force teacher educators to implement some sort of screening strategy.

It is not suprising that GPA is the most popular selection criterion in teacher education programs. After all, teacher education programs are part of a societal institution, and a key characteristic of institutions is that selected procedures become reified and resist change. Weiss (1991) suggested that many institutional policy decisions or actions stem from precedent rather than thoughtful choices. University programs use GPA because it provides simple, concrete, and seemingly "objective" means for comparing students, teachers, and programs. Furthermore, study of PETE faculty suggests that, due to their own history and career orientation, they are most likely to be custodians of the bureaucracy as it exists (Mitchell \& Lawson, 1986).

Socialization researchers have pursued an interesting alternative line of inquiry. Rather than seeking screening criteria, interest has been directed toward perspectives of high school and first-year university students toward teaching in physical education (Dewar, 1984; Hutchinson, 1993; Templin, Woodford, \& Mulling, 1982). Dewar (1984) noted inconsistencies between what students believed was required for success in physical education and research findings. She found that students believed the role of teaching and coaching was one and the same, 
involving learning to play games and teaching them to others. Furthermore, subjects interested in teaching careers also expressed a desire to create physical education programs identical to the programs that they had experienced in school. Hutchinson's work with high school students (identified as early career deciders) reflected a similar narrow and custodial orientation toward teaching in physical education.

Although work by Dewar (1984) and Hutchinson (1993) does not help with the initial screening of students, there is information available for teacher educators creating professional preparation programs. Clearly, students enter professional preparation programs with beliefs as to what a physical education teacher does, and what the curriculum should be. These views reflect an orientation toward the custodial maintenance of programs as they are currently operated with the roles of teacher and coach linked as one role rather than as two distinct roles. Accepting new recruits with a commitment to maintaining programs as they are currently designed and delivered is potentially problematic. It has been suggested that many secondary programs are destined for extinction (Siedentop, 1987). Others believe that to continue to be a viable presence in society, professions must be responsive to the changing characteristics of the people served (Argyris \& Schon, 1974). Hence, a profession composed of new recruits committed to maintaining programs that are currently troubled and that are resistant to adapting to the changing needs of the community is in jeopardy.

Data cited above point to the need to attend to the attitudes of recruits. There is an accompanying need to supply students with a vision for the future and the skills to realize that mission. Some of the theoretical territory surrounding occupational recruitment in physical education has been charted (Dewar \& Lawson, 1984; Lawson, 1993b; Templin, Woodford, \& Mulling 1982). Even though there were conceptual flaws in this initial work (Lawson, 1993b), there were implications for action. For example, Templin et al. (1982) provided some of the theoretical background for understanding how undergraduate students acquire their views regarding physical education. The authors identified attractors to and facilitators for a career in physical education, raising questions regarding the ways the profession is perceived and the existing admission standards. One possible avenue toward remediating recruits attitudes may be through modifying professional attractors, facilitators, and standards of admission. Clearly, teacher educators should play a role in providing accurate information and dispelling myths regarding each of these issues. The future study of teacher educators may provide insight into the role played by PETE faculty to influence attractors, facilitators, and standards.

Control over who gets in and who is allowed to exit programs is not, at present, tied to any strategy supported by research as a valid indicator of teaching potential. There is not a sufficient data base to guarantee that the best students are admitted and not turned away. There is not, moreover, any assurance that only competent students are released into the profession. Faced with these uncertainties, teacher educators must somehow cope with the responsibility to prepare new teachers.

\section{Preparation Role}

What is the best way to prepare teachers to become effective teachers in the schools of today and tomorrow? There appears to be little consistency in answering this question. For example, Alley (1982) cited results of a study of 230 departments of physical education from which the only course required in all departments was practice teaching. More recently, Edwards (1989) identified a trend over the past three decades toward more research- and science-based courses at the expense of dance, exercise, and sport performance classes and clinical experiences.

The diversity of preparation programs should not be unexpected. Mitchell and Lawson (1986) found that teacher educators did not agree on characteristics or traits of an outstanding physical education teacher or teacher education program. The authors theorized that one 
potential source of differing opinions may have been tied to the lack of formal training in curriculum, instruction, or supervision by the majority of the subjects. Mitchell (1988) found a similar lack of consensus on views of PETE programs, PETE professors, and ideal physical education teachers. Professors interviewed by Mitchell reported different opinions regarding these ideals; differences among subjects were found both within and across institutional affiliations. For example, opinions regarding ideal PETE programs included beliefs that programs should last anywhere from 2 to 7 years. Program content was identified as including, with a wide variety of emphasis, such things as personal skill performance, exercise science, field or clinical experience, methods of teaching courses, liberal arts, and college of education coursework. Ideal PETE faculty were characterized by a variety of attributes with no single knowledge area, skill, or value garnering even one third of the support of the subjects in the study. Perceptions of an ideal physical education teacher were similar to the perceptions of ideal methods teachers on the PETE faculty. The greatest support was expressed for the ability to communicate verbally and in writing ( $40 \%$ of the subjects) and for individuals to believe in the value of physical education as "important" ( $45 \%$ of the subjects).

Mitchell (1990b) also reported data from a study with a limited sample of future PETE professors when he described the perceptions of six doctoral candidates from one program with a pedagogy focus. Perceptions of these doctoral candidates toward the ideals described above reflected more, rather than less, variability than was evident in the larger pool of PETE professors. Hence, the variability trend in professional preparation programs appears likely to continue when viewing the potential impact of faculty views. The potential for impact on professional preparation programs also can be viewed from a perspective of political mandates. Mitchell and Earls (1987) reported on state requirements governing K-12 physical education programs across the country. In that study, a large variety of mandates for programs was reported, most probably reflecting the equally large variety of programs of physical education taught across the country. In light of Dewar's (1984) finding that many recruits wanted to reproduce programs like the ones they came through, there should be no surprise that there continues to be diversity regarding perceptions of what should be done in physical education. Another route to insight into why PETE programs are taught the way they are can be accessed through the study of the work environment of teacher educators (cf., Goc Karp \& Williamson, 1993c). Teaching loads, research demands, and reward structures must be considered along with biographies when trying to understand why teacher educators do what they do. These job-site characteristics contribute to the selection and delivery of curriculum content. Also influenced by these workplace variables will be the extent to which PETE faculty model behaviors consistent with their espoused values.

To portray all professional programs as completely idiosyncratic would be both misleading and false. Lawson (1983a) presented a series of propositions describing what programs might look like if based on findings from the socialization literature. One involved the hypothesized potential for programs to have a greater impact on students if faculty presented a consensus approach to professional responsibilities. There is some emergent research on programs that can be characterized by consensus on goals by faculty (Graber, 1993; Rovegno, 1992a). Doolittle, Dodds, and Placek (1993) reported case studies of students involved in the PETE program at The University of Massachusetts. Their initial work identified mixed success with having teacher candidates use specialized terminology, demonstrate understanding of the knowledge base, and value the teaching orientation espoused by the faculty in the program. The ultimate value of any efforts to prepare teachers must still lie in the extent to which pupils realize stated goals in programs taught by graduates of the PETE programs. Sadly, few research designs follow PETE program graduates into their jobs to explore the link between teacher education and practice in schools. Until research with this type of longitudinal design is implemented, it will be difficult to validly claim the effectiveness of any program of teacher education. 
Uncertainty about the "best" way to perform the preparation role must be overcome as the demands of practice require that something be done on a day-to-day and year-to-year basis. Another way to understand how teacher educators perform their role is to understand the related responsibility for disseminating knowledge.

\section{Knowledge Dissemination Role}

Teaching can be described as one form of knowledge dissemination. Other forms of dissemination include formal presentations at professional conferences, in-service workshop presentations, professional publications, and even informal meetings with colleagues. These forms of knowledge dissemination are avenues available to teacher educators to influence practice in schools. Put differently, there is a close link between the dissemination of knowledge and the acquisition, use, or application of knowledge to practice. But, what is it that PETE professors are trying to disseminate, and to what end?

One strategy for understanding the hypothetical linkage between knowledge production and knowledge use is presented by Miles and Haughey (1992). They reviewed literature related to knowledge use in education and identified a 30-year history of "serious thought and action about the issues involved in knowledge use in education"' (p. 242). They suggested that a key to understanding the knowledge dissemination process was to identify how knowledge is conceptualized. They identified two metaphors to illustrate their message. On one hand, knowledge is described as a "treasure chest" (p. 244). In this metaphor, they suggest that the treasure (knowledge) is precious and rare, must be guarded, and only those who are authorized may open the chest. On the other hand, a scenario is presented as illustrative of another way of conceptualizing knowledge:

Consider whether a farmer would go to the agricultural agent and say "Please, Mr. Agent, what's in your treasure chest?" A more likely query is "Look, my friend, I've got this horrible problem with black spot on my tomatoes. What can you do for me?",

It's a radically different orientation. (Miles \& Haughey, 1992, p. 245)

The "treasure chest" metaphor conjures an image similar to what exists in the formal knowledge base in physical education teacher education.

The Journal of Teaching in Physical Education (JTPE) can be considered as one type of "treasure chest" for research related to teaching in physical education. The journal has the stated mission to fill a role in presenting this type of research, and it has been identified as a popular source to faculty who read this research (Metzler \& Freedman, 1985; Mitchell, 1992c). Mitchell (1992a) studied the main contributors to JTPE over the first decade of its existence to determine who made the contributions to the physical education "treasure chest." He reported that all of the contributors held doctorates, and the list of names indicated that the majority were employed in colleges and universities; the treasure chest guards and contributors tend not to be $\mathrm{K}-12$ teachers. Hence, the prospects for contributions from and the relevance of the published work to $\mathrm{K}-12$ teachers are not promising.

The agricultural agent metaphor provides a promising possibility for linking the treasure chest to practice. Unfortunately, such an agent does not exist for physical education teachers. Locke (1969) identified the need for such an individual over 20 years ago. The fact that few fill such a role was explained by Lawson (1992c) when he suggested that programs to prepare individuals to fill such a role do not exist, professional associations do not fill this role, and universities do not reward faculty members for the performance of these duties.

Attending professional conferences and reading physical education journals are popular choices by PETE faculty for professional renewal (Mitchell, 1992c). Physical education teachers, on the other hand, report reliance on their own experiences and information provided 
by colleagues for insights into professional practice and renewal (Earls, 1981; Lawson, 1992c; Lawson, Bosel, \& Belka, 1992). Regardless of where teachers or teacher educators gain access to research findings, the likelihood for them to apply these findings to practice are hampered by at least two factors. First, there are few courses that address the use of research in practice; most courses offer discussions of findings through traditional lectures or allow students to interact with variables in laboratory settings (Lawson, 1992c). Second, the professional literature reflects minimal attention to the use or application of research (Lawson, 1992c; Mitchell, 1991).

Russell and Munby (1991) highlighted a different potential problem when they suggested that teacher education programs are based on the premise that "propositional knowledge from lectures and books can be translated directly into practice" (p. 185). This is a false premise, the authors suggested, based on their observations of novice teachers who "explicitly reject" information from their formal education, but whose teaching continues to "develop and improve" (p. 185). Russell and Munby (1991) suggested that this "propositional knowledge" was qualitatively different from "professional knowledge" (p. 185). Research on school improvement efforts reviewed by Schwager and Doolittle (1988) pointed to a similar conclusion with regard to the type of information most valued by teachers. Highest value was attributed to practical information that would have "a direct influence on real, day-to-day school problems" (Schwager \& Doolittle, 1988, p. 240).

There would appear to be different types of knowledge drawn on by practitioners to help them function in their role. The following terms are offered in an attempt to identify some synonyms that exist in the education, physical education, and other literature related to concepts of knowledge. These concepts are helpful when applied to the ways in which teachers and teacher educators gain insights into their practice.

Knowledge Types. Epistemology is the study of knowledge and involves more complexity than can be adequately addressed here. Some simple but widespread interpretations of knowledge types involve dichotomies. In education, for example, Calderhead (1988) distinguishes "academic knowledge"' from " practical knowledge." These terms would appear to coincide with what Russell and Munby (1991) characterized as "propositional knowledge" and "professional knowledge." In the physical realm, Newell (1990) refers to these concepts as "declarative knowledge" and "procedural knowledge" respectively. More generically, Ryle (1949) has identified these concepts as "knowing that" and "knowing how." Applied to physical education, examples of the first type of knowledge in the dichotomous pairs listed above (i.e., academic, propositional, declarative, and "knowing that") might include information drawn from motor skill performance analysis, game strategy theories, and pedagogical research. Included in these categories of knowledge, for example, would be the following: knowing the correct parts of the fingers used in dribbling, what a correct follow-through is supposed to look like on a set shot, where to position oneself when playing defense; knowing the theory of how and under what circumstances to run different offensive plays, how and when to implement different defensive formations; and knowing why active supervision is important and the theory of how it should be done. These types of knowledge are derived from controlled, contrived, and theoretical situations. As a result, many teachers struggle to see applications of these knowledge types to their own settings because teachers are often faced with many students, a large range of skill levels, poor facilities, and little equipment; these practical conditions do not match well with the conditions under which the knowledge was created.

The second type of knowledge applied to physical education (i.e., practical, professional, procedural, and "knowing how") would support a teacher's ability to apply theoretical principles to real students in real settings. The ability to take 30 students with various cultural, language, and skill backgrounds through a safe and educationally valuable lesson on basketball with two baskets, two basketballs, and one-half of a basketball court, would represent this 
type of knowledge. This second type of knowledge allows teachers to apply the first type of knowledge - to actually teach students how to dribble, shoot, defend, and play the game. Put differently, knowing how to dribble and being able to teach others how to dribble are different skills reflecting different types of knowledge. Seeking what was identified as practical knowledge, professional knowledge, procedural knowledge, or "knowing how" from colleagues and informal interactions is a reasonable and predictable practice. After all, colleagues function in situations much like one's own, and if a practice works for one teacher, why not for another? In contrast, academic knowledge, propositional knowledge, declarative knowledge, or "knowing that" often comes from ivory-tower researchers, not members of the school community (see Williamson, 1990b). Furthermore, the knowledge is often constructed in controlled experimental situations rather than in the "messy" reality of most teaching situations where extraneous variables are beyond the "control" of the researcher but have a major impact on the teacher.

Another interpretation of knowledge types in education was presented by Shulman (1987) when he identified seven types of knowledge relevant to teachers (p. 8). The taxonomy provided by Shulman may help in identifying some of the complexity involved with studying knowledge related to teaching, but one category in particular illuminates professional concerns regarding knowledge acquisition strategies and the resulting impact on practice. Shulman (1987) refers to "pedagogical content knowledge" as "that special amalgam of content and pedagogy that is uniquely the province of teachers, their own special form of professional understanding"' (p. 8). This category reflects an attempt to move beyond simplistic dichotomies and to address the intersection of "knowing that" or declarative knowledge and "knowing how" or procedural knowledge. Inherent in the creation of this category of knowledge is respect for the ways teachers must make adaptations to generic research knowledge with respect to the unique attributes of their own subject matter. That is, when researchers report success with a form of teacher questioning patterns in a fifth-grade classroom setting, there is no guarantee that the results will generalize to other settings. Findings from a study where students work alone with math problems while seated in desks tend not to generalize readily to physical education settings where students are free to move around with interactive challenges. It is this pedagogical content knowledge that teachers call upon to make decisions about how pedagogical research blends with the unique nature of the subject matter in their unique setting.

Editorial boards, peer reviewers, and the marketplace exert some degree of control over the quality of information offered at conferences, workshops, and in publications. Hence, information gathered from these sources by teachers is most likely accurate. Personal experiences, classes, and informal discussions are popular choices for gaining insight into practice, yet there are few formal mechanisms for controlling these types of influence over knowledge acquisition. Views of the extent to which this absence of formal control is problematic for teaching are tied to conceptions of how professionals learn.

Professional Learning. Exclusive reliance on one's own experience and the experiences of colleagues is potentially problematic. Argyris and Schon (1974) characterized a concern through two models of learning for professionals, contrasting "single-loop" and "double-loop" learning (p. 19). Single-loop learning is described as the process of learning new strategies to overcome obstacles and accomplish goals. Argyris and Schon (1974) describe this type of learning as especially useful for limiting the amount of time invested in studying "the highly predictable activities that make up the bulk of our lives" (p. 19). In contrast, double-loop learning involves an alternative approach to dealing with obstacles and goals. Rather than searching for ways to get around obstacles and accomplish accepted goals, coping strategies include the reexamination of obstacles with an eye toward prevention. In addition, reconsidering overall goals is not ruled out as another possible alternative in double-loop learning. 
Total reliance on single-loop learning is potentially problematic. One possible outcome is societal dissatisfaction with services provided by the professional group. Another probable outcome is the perception by the professional group that those who do not accept their services are missing something important, or that the clients (students) are somehow flawed because they do not benefit from the intervention (teaching; cf. Grossman, 1990); the possibility of the service not fitting client or societal needs is not considered.

Societal needs change across time, and the knowledge available to inform professional practice continues to grow rapidly. Professionals who do not attend to societal needs and a changing knowledge base approach what might be called "physical education malpractice" by attempting to provide services that may be neither needed nor wanted. The institutional mechanism created to prevent this schism between societal needs and professional practice involves an expectation for professionals to be involved in the creation of new knowledge.

\section{Knowledge Production Role}

Few teachers or teacher educators appear to read research. Another strategy for gaining new knowledge, therefore, is to participate in the creation of new knowledge or research. Wisniewski and Ducharme (1989b) suggest that education professors should be characterized by "professors who are active producers and consumers of scholarship" (p. 152). Indeed, these authors characterize scholarship as the sine qua non of the professorial life. The perceived importance of the role also extends to physical educators in higher education, at least through their responsibility to interpret current knowledge for students (Ross, 1981). That is, as experts expand the knowledge in a given field, these faculty members have a responsibility to help their students understand how diverse fields of study impact upon their future practice as teachers. With a slightly different purpose in mind, Silverman (1987) suggested that at least one goal for physical education scholars should be to "train the future generation of researchers and practitioners to appropriately plan, understand, and value the research enterprise" (p. 69). Almond and Thorpe (1988) go further than Silverman, suggesting that all teachers need to be more reflective about their practice. They go on to link this reflection with the accompanying need for a "commitment to write and share one's experiences" (p. 227).

Another strategy for helping teachers and teacher educators create knowledge has been the proposal that they work together. Herrick (1992) presented a brief history of collaborative action research between schools and universities. He also described an example of a program of collaborative action research that evolved over a 12-year period. In physical education, Schempp and Martinek (1988) made a case for the value of collaborative research, which involves multiple perspectives in contributions to the knowledge base. Martinek and Butt (1988) presented an applied example of action research in physical education, which they offered as a model to facilitate "mutual growth and respect" (p. 220) between teachers and teacher educators.

Many authors operate with an implicit assumption that professionals have the responsibility to contribute to a knowledge base. Furthermore, this knowledge base should reflect accumulated wisdom and be available to others to inform their professional decisions. Here is the implied link between research or knowledge creation and practice or knowledge application. Using Miles and Haughey's (1992) "treasure chest" analogy, everyone should contribute and have access to the knowledge base (treasure). Other authors have portrayed the link between research and practice in a less discrete fashion. For example, Boyer (1990) presented an expanded view of scholarship to include discovery (defined as original research), integration (drawing together and bringing new insight to existing research for others), application (a dialectic interaction between the theory and practice of service), and teaching. This expanded view of scholarship is a response to the pressure to publish, the reward structures of universities, 
and the desire to provide better undergraduate education. From this perspective, good teaching as practice is simultaneously a form of scholarship.

Philosophical Orientations. Clearly, there are different conceptions of what research is and how knowledge gained from research should inform practice. The question "what is knowledge?" is answered and all associated understandings stem from underlying epistemological assumptions. Tom and Valli (1990) present four epistemological traditions with accompanying guidelines for the typical form and purpose of knowledge along with embedded values. The four traditions are identified as positivist, interpretive, critical, and craft. Knowledge, for positivists, involves collecting lawlike generalizations that facilitate prediction and control of the relationships among variables. Knowledge is generally acquired through what Rosenshine and Furst (1973) characterized as the descriptive-correlational-experimental loop wherein variables are manipulated in controlled settings to quantify outcomes. In education, positivists seek generalizations that can be applied to improving teaching. Lawson (1985) frames the positivist linkage between knowledge and practice as "rooted in the belief that new knowledge and skill, developed in universities, will readily transfer into the work organization" (p. 11). Selecting what generalizations to apply to practice depends upon the values of the teacher; the generalizations themselves, however, are considered value-neutral. Collecting generalizations is intended to be lawlike (i.e., "if this then that" format) and cumulative (i.e., each piece of research builds on previous work and contributes to future work). From this perspective, teachers or researchers identify problems, and researchers provide answers. If answers do not exist, there is a prescribed methodology (hypothesis, description, observation, correlation, experimentation) to seek answers that would be used and added to the body of knowledge. PETE faculty in a positivist orientation would study teaching and identify rules for teaching that will generalize broadly. Knowledge utilization is evidenced by the application of principles to given situations.

The interpretive tradition is tied to the search for knowledge linked to specific contexts and often created through the meaning attached to events in a context-dependent manner. Lawlike generalizations that are context-free are not focal in this type of research. Researchers, according to Carr and Kemmis (1983), provide insights into behaviors and actions, helping teachers deepen their insights into their own settings and to influence action through critical reflection. The way that participants make meaning of events is focal in understanding what goes on in a particular setting. PETE faculty working from an interpretive tradition would study individual settings. The value of this lies in the extent to which researchers would enlighten professionals to better understand their own work site. For the interpretivist, there is little if any value in widely disseminated publications other than to the extent that such publications enlighten others in methods of inquiry. Evidence for knowledge utilization exists in the extent to which practitioners reflect on their own practice and act thoughtfully in light of their enhanced understanding of the match between their motives and actions.

Researchers in both the positivist and interpretivist traditions espouse a value-neutral stance toward their work. For positivists, all values are outside the context of study because they cannot be quantified; social phenomena exist as separate and observable conditions. Interpretivists work within a framework that recognizes social phenomena as socially constructed (cf. Berger \& Luckmann, 1966), and the values of participants in a given setting are crucial to understanding what happens. Both positivists and interpretivists hold their own values and beliefs separate from what they study so as to consider "objectively" that which they study. Positivists provide research findings that, it is hoped, will be adopted by everyone to achieve specific outcomes. Interpretivists provide insights to help practitioners better understand their own practice and to choose their own thoughtful course of action from a position informed by an awareness of alternatives.

The critical perspective is oriented toward a stated value of equality and justice-there is no pretense of value neutrality. The common conviction of individuals operating with this 
perspective is that educational and social institutions and relationships are neither equal nor just. The critical perspective is offered with the belief that practitioners are often blind to the injustices and inequities in their own settings. Knowledge is created through the value-laden analysis of social structures and relationships, which are believed to be inherently unfair. Knowledge dissemination occurs through whatever formal (e.g., professional and public literature, professional and public lectures) and informal channels (e.g., private discussions, workshops) will enable practitioners to transform their workplace, their practice, and the lives of their clients (i.e., students). Knowledge utilization is evaluated in the extent to which any of these transformations actually occur. Hence, the critical perspective is presented as a means to explore ways to render educational and societal institutions more equitable for all individuals. Research is seen as valuable in the extent to which it brings members of society closer to equality. Researchers are, therefore, not the neutral observers portrayed by positivists and interpretivists. In the critical tradition, Carr and Kemmis (1983) identify a new role for the researcher "whereby his or her participation in the development of knowledge is comprehended as social and political action which must be understood and justified as such" (p. 148).

Finally, the craft orientation is identified by Tom and Valli (1990) as "outside recognized epistemological traditions yet [it] is generally acknowledged to be the dominant orientation among both classroom teachers and teacher educators"' (p. 377). There are no recognizable research methods or researcher roles per se. Knowledge is derived from personal practice or from formal and informal discussions with colleagues, and it is valued by the extent to which it allows teachers to achieve their goals. Tom and Valli (1990) go on to suggest that there is little consensus on what is meant by craft knowledge; adjectives such as "traditionalism," " "apprentice training," " heritage of common sense," " folklore," and "accumulated experience of practitioners" are used (p. 377). Knowledge is created through doing because what qualifies as knowledge has qualified because it has passed the test of practical implementation in the real setting. Knowledge is disseminated through personal experience and through the experience of colleagues who have tested and approved techniques in their own settings. Evidence of knowledge utilization is essentially rhetoric in that practice is de facto evidence of knowledge utilization because one must know something to be able to do anything.

The practice of teachers and teacher educators is dominated by a craft orientation toward knowledge creation, dissemination, and utilization (Lawson, 1985; Tom \& Valli, 1990). What is valued is that which survives the test of application in practice. In effect, knowledge is at once generated, disseminated, and applied, in the form of practice. Dissemination may also occur separately from practice through discussions with colleagues. Dissemination through more formal means (e.g., books, refereed publications, formal national and international presentations) are not typically valued because these sources are not often consulted for insight into practice. Hence, teacher educators (many former teachers themselves) straddle a difficult boundary position between the schools and higher education. The tension between the demands of these two worlds has yielded programs and faculty that are, in many ways, at odds with competing views of knowledge for practice.

Teachers and teacher educators function with a craft knowledge perspective. Practical insights into practical concerns are valued in the school setting. In the world of universities, on the other hand, value is attached to that which is tacitly identified as important through peer acceptance rather than through student achievement. This acceptance is measured through publications in professional journals, presentations at professional meetings, and grants received from external sources, not by student test scores. The value of research has been transferred from the act of creating new knowledge to becoming a commodified proxy measure of acceptance (e.g., numbers of refereed publications and professional conference presentations). Hence, value (in the form of practical applications that actually improve practice) has been displaced. Research is a commodity in higher education, where citations are bartered for merit 
raises, promotions, and tenure. Practical applications of research to practice-focal in three of the four philosophical orientations described above-are not important attributes in higher education; peer review, invited speeches, and funded studies are the currency traded.

In an analysis of academic life in higher education, Clark (1987) described what he called the paradox of academic work as the fact that higher education faculty spend most of their time teaching although research is the most rewarded activity. Clark went on to suggest that this paradox "really indicates that things are broken and should be fixed" (p. 99). Boyer's (1990) proposition to reconsider definitions for scholarship was one attempt at "fixing" the problem. However knowledge is conceptualized, there is a concern about the extent to which professors actually pursue the traditional research task. For example, Sizer and Powell (1969) suggested that "the unreflective, unquestioning (if frighteningly well-meaning) professor is still, alas, the rule. May his tribe decrease" (p.73).

\section{Conclusions and Implications}

Teacher educators have the potential to influence practice in schools in at least four related ways. They serve as gatekeepers, create and run programs to prepare teachers, disseminate knowledge, and are responsible for creating new knowledge. Research on the roles played by teacher educators has provided answers and raised new questions about how they contribute to the quality of practice in schools.

As gatekeepers, PETE faculty influence practice in schools by determining who may and who may not teach. Initial research suggests that decisions related to admission, retention, and graduation are tied to a student's GPA almost exclusively. It is also apparent that GPA is not a good predictor of subsequent success in teaching. Why this evaluative criterion persists is the result of many factors among which is Sarason's (1982) observation that often "we have a tendency to assume the way things are is the way things should be" (p. 96). Whether or not there are better techniques for evaluating the potential for success in a teacher preparation program and ultimately in teaching is a potentially valuable line of research into the practices of teacher educators. A related concern involves whether the best potential teachers are attracted to the profession in the first place. Because many teachers who leave the profession are disproportionately from the more academically talented (Lanier \& Little, 1986), there is concern over both who is attracted to and who stays in a career in teaching. Accurately representing the profession to new recruits and announcing what the teaching profession entails, needs more attention.

In the preparation role, PETE faculty prepare new professionals for a career in teaching. However, PETE faculty do not appear to share perceptions of what should happen in school physical education programs, what ideal teachers should do, what ideal PETE programs should look like, or what ideal PETE faculty should do. There is less information available on what actually happens in PETE programs, what impact professional preparation programs have on the subsequent teacher behaviors, or what impact professional preparation programs have on learning in schools. Longitudinal research designs that address these linkages are desperately needed to accurately assess the impact of PETE programs.

The knowledge dissemination role may be met in a variety of ways including informal conversations and meetings with colleagues, presentations at conferences and workshops, publications, and teaching classes. A variety of simple dichotomous representations of knowledge types indicate that some dissemination strategies will be valued more highly than others. Teachers live in a world where decisions must be made constantly, and to be of value, information must be immediately applicable. Hence, practical knowledge, professional knowledge, procedural knowledge, or "knowing how" and even pedagogical content knowledge are often sought from colleagues and informal interactions since this knowledge comes with 
a type of "face validity" and is most often readily applicable. In contrast, academic knowledge, propositional knowledge, declarative knowledge, or "knowing that" are more consistent with the formal knowledge transmission standards of higher education in which practical application is not a necessity.

How teacher educators cope with the conflicting expectations between research and knowledge dissemination is an intriguing area for future research. Some would suggest that problems in coping with these conflicting expectations have led to a "knowledge gap" between theory (or research) and practice. The notion of a gap is not new (Anderson, 1973; Kneer, 1986b; Siedentop, 1980b). Implicit in the work identifying a gap is the suggestion that there is a problem. Specifically, the concern is that teachers are behind the times and teach students outdated material in outmoded ways. It is important to note that there are other ways to interpret the relationship between what teachers do and what others believe should be done. Resistance to change may be more than an impediment that must be overcome in order to implement some novel instructional strategy or curricular innovation. Resistance to change by teachers and PETE faculty may be a defense mechanism that prevents the acceptance of instructional strategies or curricular innovations that are ultimately deemed inappropriate for the students or community. Put differently, it is possible that a valuable service to students and communities is provided by screening unproven and untested materials prior to implementation.

Whether or not new knowledge is used by either teachers or teacher educators is a related but different concern from the responsibility to produce new knowledge. The creation of new knowledge is a form of cultural capital for teacher educators. Certain types of publications and presentations are like commodities that can be accumulated to use in exchange for promotion, tenure, and merit pay increments. Impact on practice is sometimes (cf. Metzler, 1992), but not always, espoused as a goal of research. Lindblom (1990), for example, argued that research has value as a path toward enlightenment rather than just for tangible applications to practice. Locke (1985) furthermore argued that searching for solutions to school problems and helping teachers decide what is best is a misunderstanding of the purpose research should serve. It should not be surprising to discover that the research literature appears to have little that would be of interest to many teachers or teacher educators (Mitchell, 1991); it is possible that such application is not the purpose of the producers of this literature. An interesting question to address, therefore, is, "What is the purpose driving contributors to the literature in physical education?"

Few teachers or teacher educators contribute to the formal knowledge base, and few report using formal research to inform their practice. Only in the positivist philosophical orientation toward knowledge is such a linkage identified. Other orientations (interpretivist, critical, and craft) predict other forms of linkage between knowledge creation, dissemination, and utilization. The study of PETE faculty efforts regarding knowledge creation, dissemination, and utilization should include sensitivity to these different perspectives. With an expanded view toward different types of knowledge, concerns about knowledge may be interpreted differently. For example, concern about the creation and expansion of the formal knowledge base, composed of lawlike generalizations that are context free, is most relevant only in the positivist orientation. However, if PETE faculty are not engaged in active dissemination of knowledge, there will be repercussions in the higher education communities where this commodity is the currency of trade. There also are concerns about whether or not PETE faculty are engaged in any type of scholarship anyway. Many positivists would claim that identifying different philosophical orientations is simply a ruse to cover the fact that no scholarship occurs. Hence, perhaps PETE faculty would benefit by viewing publishing and formal speaking as forms of documentation of scholarly activity, rather than exclusively as forms of knowledge dissemination. Another interesting question relates to the potential modeling effect of PETE faculty and knowledge creation. Encouraging teachers (prospective and practicing) 
to be more reflective and willing to share their insights, if such encouragement exists, is unlikely to fall on receptive ears if PETE faculty are not engaged in this activity.

Finally, the potential for practice in schools to be influenced by PETE faculty through the application of the most current or "cutting edge" knowledge has been questioned. If teachers and teacher educators hope to meet the demands of a changing society with changing needs, it may be necessary for what Argyris and Schon (1974) have identified as "doubleloop" learning to occur. Without questioning practices and ultimate goals, it is impossible for professionals to guarantee that their services actually meet the needs of their clients. It is this professional service responsibility that highlights the liability of minimal involvement with knowledge creation or with "cutting edge" information; without new information and theories about alternative instructional techniques, content innovations, and program goals, teachers are destined to offer instruction that does not match the changing characteristics of the subject matter or the changing needs of the students and community.

Much remains to be explored about PETE faculty. Links between PETE faculty actions and the quality of practice in schools have been highlighted in this chapter along with questions warranting further study. Dodds (1989) and Lawson (1991a) also have proposed some of what might be examined with regard to PETE faculty, making a strong case for Lawson's suggestion that "research on PETE professors is not a luxury apart from practice; it is a practical necessity”' (p. 230). 